\title{
A REPRODUÇÃO DA ESPÉCIE HUMANA EM QUESTÃO NAS UTOPIAS FEMINISTAS DE CHARLOTTE PERKINS GILMAN E MARGE PIERCY
}

\section{Lucia de La Rocque*}

Resumo: Uma das características femininas mais manipuladas pelo patriarcado tem sido o fato de que, para que a reprodução da espécie humana ocorra, a geração do novo ser deva ocorrer exclusivamente no corpo da mulher. Esse dado biológico que, apesar das mais avançadas biotecnologias, ainda não foi passível de alteração, adquiriu matizes culturais que relegaram as mulheres à posição de meras reprodutoras da espécie humana, "cálices sagrados", onde seriam gerados os homens, considerados os verdadeiros motores da sociedade. As distopias feministas, desde o recentemente redescoberto Swastika Night (1937), de Katharine Burdekin, até o best-seller The Handmaid's Tale (1985), de Margaret Atwood, têm explorado essa visão humilhante da mulher. Por outro lado, as utopias feministas também não têm deixado de enfocar essa importante questão, imaginando então alternativas que liberariam a mulher dessa determinação biológica. O presente artigo demonstra como o romance Herland (1915), de Charlotte Perkins Gilman, cria uma utopia separatista, enquanto que Woman on the Edge of Time (1976), de Marge Piercy, prevê uma biotecnologia reprodutora que dispensa totalmente o separatismo, de que Gilman foi pioneira mas que, alimentado pelo momento político, proliferou nas utopias feministas dos anos 60 e 70 .

Palavras-chave: Utopias Feministas. Reprodução Humana. Separatismo. Biotecnologia.

O sonho de um mundo melhor deve ter acompanhado a humanidade desde seu berço. A literatura, através dos séculos, registrou esses sonhos, A República, de Platão, sendo separada do trabalho de Thomas More, Utopia, por quase 2000 anos. Essas sociedades perfeitas eram críticas das mazelas das sociedades reais de

- Pesquisadora da FIOCRUZ e Professora Adjunta da Universidade Estadual do Rio de Janeiro, é Doutora em Ciências e Mestre em Literatura Comparada. 
seus autores. No entanto, as utopias transmitiam a crença de que, à medida que o mundo se desenvolvia e especialmente depois da revolução de conhecimento dos séculos XVII e XVIII, à medida que a ciência e tecnologia penetravam nos maiores e menores espaços possíveis, nosso mundo viraria a edição terrena do Paraíso. Entretanto, como Booker pondera:

Até o século XIX, muito dos progressos tecnológicos previstos pelos primeiros cientistas, como Bacon, já tinham sido alcançados, mas muito deles já deixavam entrever que a ciência não teria um efeito totalmente emancipatório sobre a humanidade. De maneira muito evidente, os avanços tecnológicos, possibilitados pelo progresso da ciência, contribuíram para uma revolução industrial na Europa ocidental, que tornou o imperialismo uma realidade prática para o mundo todo, ao mesmo tempo em que mostrava ser tudo menos emancipadora para as massas de trabalhadores europeus explorados, que se viram de repente atrelados às máquinas a serviço da indústria [...] Ao final do século, a ciência e a tecnologia se haviam tornado símbolos não só da capacidade humana, mas também de sua fraqueza e limitação [...] Não surpreende, pois, que as visões utópicas do século XIX mostrem uma forte ambivalência em relação à ciência e à tecnologia. Por exemplo, a mecanização desempenha um papel importante na eficiência industrial da utopia socialista de Edward Belllamy, intitulada Looking Backwards (1888), mas em Erewhon (1872), escrito por Samuel Butler, as máquinas foram totalmente banidas devido à sua tendência de tiranizar os homens que as fizeram $(1994$, p. 6).

A ambivalência a que Booker se refere acabou, então, acarretando uma mudança de atitude refletida na produção de obras literárias, as distopias, que imaginam futuros tenebrosos e que, a partir da segunda metade do século XIX, inserem-se no campo nascente da ficção científica, como The Time Machine (1895), de H.G.Wells, que prevê um tempo em que a rígida divisão social entre os seres humanos se aguça de forma absolutamente horripilante. No século XX, marcado pela ascensão dos regimes totalitários e de um capitalismo desenfreado e impiedoso com os desprivilegiados, essa produção 
literária distópica se avoluma, produzindo os proféticos Brave New World (1932), de Aldous Huxley, e Nineteen Eighty-Four (1949), de George Orwell, que lidam com o controle total dos cidadãos por Estados superpoderosos.

O controle sempre envolve a mente e o corpo, e, portanto, afeta diferentemente homens e mulheres. Uma das características femininas mais manipuladas pelo patriarcado, através dos tempos, foi o fato de que, para que a reprodução da espécie humana ocorra, a geração do novo ser deva ocorrer exclusivamente no corpo da mulher. Esse dado biológico, que até hoje, apesar das mais avançadas biotecnologias, ainda não foi passível de alteração, adquiriu matizes culturais que justificaram a relegação das mulheres à posição de meras reprodutoras da espécie humana, "cálices sagrados", onde seriam gerados os homens, considerados os verdadeiros motores da sociedade. As distopias feministas têm explorado intensamente essa visão humilhante da mulher. No recentemente redescoberto Swastika Night (1937), Katharine Burdekin imagina um futuro dominado há centenas de anos pelo nazismo, no qual as mulheres são mantidas em gaiolas e restritas a um estado bestial de ignorância e apatia. No bestseller The Handmaid's Tale (1985), de Margaret Atwood, um golpe cristão-fundamentalista no futuro próximo dividiu as mulheres em castas e a casta das Aias ficou restrita, como as mulheres engaioladas de Burdekin, à função de bestas reprodutoras. ${ }^{1}$ Por outro lado, as utopias feministas também não têm deixado de enfocar essa importante questão, imaginando então alternativas que liberariam a mulher desse papel reprodutor como estigma biologicamente determinado. Pretendo então, neste artigo, discutir os modos bastante diversos pelos quais os romances Herland (1915), de Charlotte Perkins Gilman, e Woman on the Edge of Time (1976), de Marge Piercy, apresentam essas alternativas, refletindo o contexto social da época em que as obras foram produzidas.

1 Para um melhor entendimento do conteúdo crítico dessas distopias, sugere-se a leitura do artigo de Raffaella Baccolini, "Gender and Genre in the Feminist Critical Dystopias of Katharine Burdekin, Margaret Atwood and Octavia Butler" (2000). 
A norte-americana Charlotte Perkins Gilman, que viveu entre os anos de 1860 e 1935, preferia ser reconhecida pelo seu trabalho como líder feminista e escritora de não ficção, sempre insistindo que sua obra ficcional servia como meio de promover sua mensagem. Gilman levou incansavelmente a cabo, através de seus livros e conferências, a luta pela emancipação sócio-econômica da mulher, seu livro Women and Economics (1898) tem sido usado como livro-texto em universidades norte-americanas e traduzido em sete idiomas. ${ }^{2}$ Aliás, muitas das idéias contidas nesse livro estão espelhadas em Herland, confirmando a ligação entre a ficção de Gilman e suas fortes convicções a respeito da posição injusta à qual a mulher havia sido relegada na sociedade.

O narrador de Herland é um sociólogo, Vandyck Jennings, o que ressoa com a atribuição do papel, por parte de Gilman, ao "sociólogo" de pesquisador da função do sexo na cultura humana. Jennings se aventura na exploração de terras desconhecidas com seus dois amigos, Terry $\mathrm{O}$ Nicholson, milionário que financia as expedições, e Jeff Margrave, um médico. Eles escutam rumores sobre um lugar remoto e inacessível povoado exclusivamente por mulheres, e lá conseguem chegar no avião de Terry, permanecendo por um ano. Os homens são tratados como prisioneiros de luxo pelas matriarcas até que se tornem mais "civilizados", capazes de entender a civilização perfeita, livre de mácula de crime ou de qualquer tipo de violência, da qual o sexo masculino está ausente há dois mil anos. No seu período de aprendizado da linguagem e dos costumes locais, os três descobrem que tal fato se deveu à morte de todos os homens da população original numa guerra, ao isolamento geográfico que se seguiu e ao posterior aparecimento do fenômeno da partenogênese espontânea entre algumas mulheres, cujas filhas herdaram a mesma capacidade. Os três homens sentem dificuldade de explicar o modo bárbaro pelo qual as mulheres são tratadas em seu país de origem para Celis, Alima e Eliador, as três jovens que voluntariamente se envolvem com os visitantes a fim de reviver a possibilidade de descendência masculina

2 Ver Harris e De La Rocque (2002, p. 15). Todas as traduções dos textos citados foram feitas pela autora do presente trabalho, com exceção da que consta na primeira nota, que foi da autoria de Maria Celina Hahn. 
em Herland e assim facilitar o contato com o resto do mundo. Infelizmente, a relação entre Terry - o único dos três homens que definitivamente se encaixa no estereótipo do machão - e Alima deteriora-se rapidamente, culminando numa tentativa de estupro e, finalmente, no exílio dos homens de Herland.

De todos os vôos imaginativos perpetrados por Gilman em Herland - o lugar inacessível pelo isolamento geográfico, contrastado com a facilidade dos exploradores em encontrá-lo, a sociedade mais que perfeita por eles descoberta -, o que chama mais atenção é o modo de reprodução da população exclusivamente feminina. A partenogênese é moeda corrente na ficção científica, mas ela normalmente é resultado de anos de pesquisa dentro da "realidade" dessas obras ficcionais - o que poderia, nos dias de hoje, não estar longe da verdade, se considerarmos o relativo sucesso da clonagem de Dolly. ${ }^{3}$ Embora seja inegável o fato de Herland ter sido escrito décadas antes dessas outras obras em que a partenogênese aparece dentro de uma perspectiva mais "científica", frutos de um contexto de desenvolvimento tecnológico inegavelmente mais vultoso, creio ser interessante determo-nos nesse processo de partenogênese espontânea concebido por Gilman. A primeira mulher partenogenética em Herland é considerada uma "Mulher Maravilha", e dá origem a cinco filhas, a quem

toda a nação de mulheres circundava com cuidados amorosos, e esperava, entre uma esperança sem limites e um desespero igualmente desmedido, para ver se elas também, seriam mães ...e elas foram! Assim que alcançaram a idade de vinte e cinco anos elas começaram a conceber. Cada uma delas, como sua mãe, teve cinco filhas [...] e todo o espírito do país mudou do luto e mera resignação corajosa para uma alegria cheia de orgulho (GILMAN, 2003, p. 98).

3 A polêmica em torno da clonagem de Dolly é magistralmente discutida no livro de Gina Kolata. Clone: os caminhos para Dolly. Rio de Janeiro: Campus, 1998. Quanto a obras fictícias que lidam com a questão da partenogênese, podemos citar o conto "When it Changed", de Joanna Russ, assim como o romance The Female Man, da mesma autora. 
Todas as mulheres de Herland comemoram a maternidade, que é a preocupação central desse país. No entanto, como Somel, a matriarca designada para ser a professora do narrador Vandyck, explica, houve um momento na história do país em que se tornou absolutamente necessário limitar o processo partenogenético:

Nós estávamos tendo que racionar alimentos antes de chegarmos a uma solução [...] Mas nós conseguimos lá chegar. Veja bem, antes que a gravidez ocorra com qualquer uma de nós, há um período de exaltação suprema - todo o ser é elevado e tomado por um desejo concentrado pela criança a vir. Nós aprendemos a antecipar esse período com o maior dos cuidados. Freqüentemente nossas jovens, aquelas que ainda não haviam experimentado a maternidade, a adiavam voluntariamente. Quando aquela profunda demanda interior por uma criança chegava, ela se envolvia de forma deliberada no trabalho mais ativo, tanto físico quanto mental; e o que é mais importante, compensava seus desejos através do cuidado intenso com os bebês que nós já tínhamos (GILMAN, 2003, p. 57).

Fica aí mais que claro não só o caráter coletivo dessa maternidade, como também o controle total, por parte das mulheres de Herland, de seu processo de reprodução. Como diz Bernice Hausman:

Como muitas feministas da atualidade, Gilman viu que a liberação da mulher do que nós consideramos "expectativas de gênero" estava ligada, de forma inextricável, ao seu papel na reprodução biológica: o quanto de controle elas tinham sobre a sexualidade, como a sociedade organizava o cuidado com as crianças, como o mundo resolvia a questão da maternidade e as práticas a ela relacionadas. No âmago da sua análise está o corpo feminino como produto de uma evolução tanto biológica quanto sociológica. É esse o motivo de a partenogênese ser crucial para o projeto de Herland, mesmo sendo o seu elemento mais fantástico.

A partenogênese é uma metáfora para o controle, por parte das mulheres, da reprodução. O fato de ser um processo biológico demonstra o desejo de Gilman de tornar o corpo biológico central aos arranjos sociais dos 

FEMINISTAS DE CHARLOTTE PERKINS GILMAN E MARGE PIERCY

quais faz parte - ao invés de tratá-lo como uma substância a ser alterada de tal forma a acomodar as normas da sociedade, que é a maneira pela qual ela interpretava as expectativas da sua cultura em relação às mulheres (HAUSMAN, 1998, p. 13).

Toda essa imbricação entre biologia e cultura perpassa também a mais conhecida obra de não ficção de Gilman, o já mencionado Women and Economics, em que a ativista feminista afirma a relação entre a evolução orgânica e a economia: "Na mais simples combinação de células primordiais, a força que as juntou e as manteve juntas foi a necessidade econômica. Estas que se juntaram sobreviveram, e as que não o fizeram pereceram" (1995, p. 10). Fica patente, então, que a estranha partenogênese, imaginada por Gilman como força motriz da reprodução em Herland, é um espelho dessa sua visão de integração entre dois paradigmas, o orgânico e o social, numa época em que o biológico era considerado justificativa para as desigualdades sociais entre os gêneros.

Gilman, em Herland, precisou manter as mulheres exercendo controle total sobre seu potencial reprodutivo; a possibilidade da inclusão dos homens nesse processo - embora considerada em determinado momento, quando as três jovens, com a aquiescência de toda a comunidade, oferecem-se como voluntárias para se envolverem com os visitantes - é totalmente afastada no final do livro, após a frustrada tentativa de Terry de estuprar sua mulher Alima. Fica patente que, para Gilman, as mulheres ficam muito melhor sozinhas.

Os movimentos feministas dos anos 60 e 70 contribuíram muito para que o separatismo de Herland fosse precursor do encontrado em várias outras utopias feministas ${ }^{4}$. Woman on the Edge of Time, de Marge Piercy, escritora americana que se filiou a causas feministas, pacifistas e ecológicas, encara a questão do controle da reprodução e suas consequiências para o equilíbrio de poder entre os sexos de forma diametralmente oposta. Nesse romance, a protagonista é Connie Ramos, mulher pobre e chicana vivendo na Nova Iorque contemporânea, que havia tido sua filha Angelina dela retirada e

4 Os já mencionados trabalhos de Russ, "When It Changed" e The Female Man, entre inúmeras outras obras da época, apresentam tal visão. 
entregue para adoção por ser considerada louca, e que fora internada numa instituição para doentes mentais. Dotada de um extraordinário poder de comunicação mental, Connie entra em contato com Mattapoisett, uma comunidade agrícola do ano de 2137, onde a ciência e a tecnologia intervêm de forma benéfica para todos. Em Mattapoisett, homens e mulheres têm absolutamente os mesmos direitos e deveres, as dualidades entre os gêneros foram abolidas a tal ponto que, no início, Connie pensa que Luciente, a cientista do futuro que a leva mentalmente para lá, é um homem. Além disso, as expectativas de nossa sociedade em relação aos papéis sexuais são totalmente subvertidas em Mattapoisett. Joanna Russ, discorrendo sobre as utopias feministas em geral, assim se posiciona em relação a Woman on the Edge of Time:

Sem estratificações em classes sociais, sem governo, ecologicamente conscientes, com uma forte ligação com a natureza, quase tribais em sentimento e quase familiares em estrutura, as sociedades dessas histórias são sexualmente permissivas[...] Monogamia, por exemplo, não entra em questão, já que a estrutura familiar é dependente do cuidado com a prole ou do contexto econômico, não da disponibilidade de parceiros. Woman on the Edge of Time é reprodutivamente o mais inventivo do grupo, com a bissexualidade (que não é percebida como uma categoria especial, e portanto não é nomeada) como norma, nascimento exogenético, tríade de pais de ambos os sexos cuidando das crianças, e os três pais amamentando os bebês (RUSS, 1995, p. 139).

O que mais choca Connie, em todos os comportamentos inusitados de Mattapoisett, é justamente a forma heterodoxa como se dá a reprodução e a maternação das crianças. É com espanto sensação que, como pode ser facilmente apreendida pelo comentário de Russ, acompanha proporcionalmente seu conhecimento crescente desse mundo futuro - e raiva que Connie descobre que homens em Mattapoisett também podem ter seios, quando estimulados hormonalmente para amamentarem seus filhos, ao ver Barbarossa, amigo de Luciente, em ação: 
Ele possuía seios. Não eram grandes. Seios pequenos, como uma mulher que tivesse seios diminutos, temporariamente inchados com leite. Então com sua barba ruiva, seu rosto de homem de quarenta e cinco anos queimado pelo sol [...] ele começou a amamentar. $\mathrm{O}$ bebê parou de berrar e começou a sugar avidamente. Uma expressão de júbilo sensual sereno se espelhou pelo rosto intelectual de professor de Barbarossa. Ele pareceu se soltar da sala, de tudo, e flutuar. Seus próprios seios doeram com saudade. Ela adorara amamentar - aquela conexão leitosa e cálida que parecia começar em seu ventre e espalhar-se pelo tronco em seus seios túrgidos [...] (que) se abriam para o rosto de flor de Angelina, o doce girassol acarinhado em seus braços [...].

Ela sentiu raiva. Sim, como qualquer homem ousava partilhar desse prazer. Estas mulheres pensavam que elas haviam ganhado, mas elas haviam entregado aos homens o último refúgio das mulheres. O que havia de especial em ser uma mulher ali? Elas haviam desistido de tudo, elas haviam deixado os homens roubarem delas as últimas sobras do antigo poder, aquelas seladas no sangue e no leite (PIERCY, 1976, p. 126).

A revolta de Connie ante a usurpação do poder feminino da amamentação pelos homens é mais que compreensível, já que, na sociedade em que vive, às mulheres, principalmente às destituídas como ela, muito pouco poder é alocado. Este não é o caso de Mattapoisett, e o ato de amamentar, assim como toda e qualquer atividade, é franqueado aos dois sexos; homens e mulheres são estimulados hormonalmente para tal fim. Em Mattapoisett, tornar-se mãe - palavra usada para quem materna, independente do sexo - é sempre uma escolha, nunca um acaso. Além disso, não há relação genética nenhuma entre os pais e os filhos; Bee, por exemplo, um dos namorados de Luciente, é negro e tem uma filha loura, Innocente, cuja maternação divide com duas mulheres, uma índia e outra de pele clara. Aliás, em Mattapoisett, contrariamente ao que ocorre em nossa sociedade, a maternação nunca é dividida com os parceiros sexuais, justamente para evitar confusões e manter tal função, que é tida em altíssima consideração, totalmente afastada de toda e qualquer escaramuça entre pares amorosos. 
O fato de cada criança ter mães com diferentes combinações de gênero, o de os homens estarem aptos a amamentar tanto quanto as mulheres, assim como a obliteração da ligação genética entre pais e filhos, foram possibilitados nesse futuro utópico pelo desenvolvimento de uma tecnologia reprodutora muito especial, que causa o primeiro grande choque de Connie em Mattapoisett; e, ao deparar-se com ela:

Connie ficou boquiaberta, seu estômago também se virou de cabeça para baixo. Numa fileira indolente, vários bebês se balançavam. A mãe máquina. Como peixes no aquário de Coney Island. Seus olhos estavam fechados. Uma fêmea muito escura chutava. Outro, um macho rosado[...]estava chorando. Eles balouçavam languidamente, como num cardume cego (1976, p. 95).

A gravidez extracorpórea é realidade há décadas na época de Luciente; somente os habitantes mais idosos passaram pela experiência de "carregar seres vivos", como eles definem a gravidez. Connie, que no mesmo dia que se dá conta desse fato também aprende sobre a falta de relação genética entre pais e filhos, revolta-se, exclamando "Como podem os homens ser mães! Como pode uma criança que não é relacionada a você ser seu filho?". A reação de Connie de espanto e raiva ante essa tecnologia reprodutora do futuro utópico, que permite a homens e mulheres exercerem o mesmo papel na maternação de crianças, vai aos poucos mudando, quando entende que, como diz sua amiga Luciente:

Foi tudo parte da longa revolução das mulheres. Quando nós estávamos rompendo as antigas hierarquias. Finalmente havia uma coisa que nós tínhamos de abrir mão, o único poder que nós tínhamos, em troca de não haver mais poder para ninguém. A produção original: o poder de dar a luz. Porque em quanto nós fossemos biologicamente presos, nós nunca seríamos iguais. E os machos nunca seriam humanizados para serem amorosos e delicados. Então nós nos tornamos todos mães. Cada criança tem três. Para quebrar a ligação nuclear (1976, p. 98). 
Esse discurso de Luciente fornece esplêndida munição para o debate sobre natureza e cultura e toda a sua imbricação com o papel dos gêneros na sociedade, estando portanto totalmente inserido na arena em que Gilman, meio século antes de Piercy, ousou adentrar. A questão da reprodução humana e o necessário elo por ela criado entre as esferas do biológico e do social e seu tangenciamento com o desequilíbrio de poder entre os gêneros foram motivo de preocupação para as duas autoras. Gilman optou por resolver tais ponderações através do separatismo, afastando os homens e deixando as mulheres com controle total da situação. Piercy, sem dúvida estimulada pelos avanços tecnológicos de seu tempo, já prevê uma biotecnologia reprodutora que dispensa totalmente o separatismo de Gilman, possibilitando a homens e mulheres participarem igualmente da reprodução e da maternação como um todo. Talvez não precisemos chegar a tal ponto, mas me parece ser inegável que a possibilidade de maior igualdade entre os gêneros, no que tange a essa premente questão, para a qual Piercy aponta, é mais que bem-vinda.

Referências

ATWOOD, Margaret. The handmaid's tale. Boston: Houghton Mifflin, 1985.

BACCOLINI, Raffaella. Gender and race in the feminist critical dystopias of Katharine Burdekin, Margaret Atwood and Octavia Butler. In: BARR, Marleen (org.). Future females, the next generation: new voices and velocities in science fiction. Boston Way, Maryland: Rowman \& Littlefield Publishers, 2000.

BELLAMY, Edwards. Looking backwards: A.D. 2000-1887. Boston: Ticknor, 1888.

BOOKER, M. Keith. The dystopian impulse in modern literature: fiction as social criticism. Westport, Connecticut: Greenwood Press, 1994.

BURDEKIN, Katharine. Swastika night . Old Westbury, New York: The Feminist Press, 1985.

BUTLER, Samuel. Erewhon. London: Trubner abd Co, 1872. 
GILMAN, Charlotte Perkins. Herland Disponível em http://etext.virginia.edu/etcbin/tocc Acesso em: janeiro 2003.

GILMAN, Charlotte Perkins. Women and economics. A study of the economic relations between men and women as a factor in social evolution. New York: Harper \& Row, 1966

HARRIS, Leila A \& DE LA ROCQUE, Lucia. "O papel de parede amarelo" de Charlotte Perkins Gilman: Resgatando a sanidade através da criatividade. Sexo, Saúde \& Educação, n. 28, 2002.

HAUSMAN, Bernice L. Sex before gender: Charlotte Perkins Gilman and the evolutionary paradigm of utopia. Feminist Studies: Fall 1998.

HUXLEY, Aldous. Brave new world. Garden City, New York: Doubleday, 1932.

KOLATA, Gina. Clone: Os caminhos para Dolly. Rio de Janeiro: Campus, 1998.

MORE, Thomas. Utopia. Boston: Bedford, 1999.

ORWELL, George. Nineteen Eighty-Four. New York: Harcourt, 1949.

PIERCY, Marge. Woman on the edge of time. New York: Fawcett Crest, 1976.

PLATO. The republic. Trans. Richard Sterling. New York: Norton, 1985.

RUSS, Joanna. The female man. New York: Bantam Books, 1975.

RUSS, Joanna.When it changed. In: ELLISON, Harlan, org. Again, dangerous visions. NewYork: Doubleday, 1972.

RUSS, Joanna. To write like a woman: Essays in feminism and science fiction. Bloomington and Indianopolis: Indiana University Press, 1995.

WELLS, H. G. The time machine. London: Heinemann, 1895. 